\title{
0 CAPÍTULO 19 DE SÃo BERNARDO: FUSÃO, TRANSFUSÃO, CONFUSÃO
}

http://dx.doi.org/10.11606/issn.2237-1184.v0i28p183-193

\section{Erwin Torralbo Gimenez}

Universidade de São Paulo (USP)

\section{RESUMO}

O estudo procura observar, em termos críticos, os traços do realismo deformador em São Bernardo, de Graciliano Ramos. Centra-se, para tanto, na análise de um fragmento: o capítulo 19. Como núcleo das tensões que caracterizam o romance, tal passagem apanha na forma o movimento dramático entre a matéria e o sujeito sob uma perspectiva desfi-guradora. Em seu desenho, o capítulo apreende a síntese de todo o enredo com três lan-ces: perplexidade na enunciação das vivências; embaralhamento dos tempos em estado de delírio; volta sem escape ao escuro presente.

\section{ABSTRACT}

This study seeks to observe, in critical terms, the traces of the deforming realism in São Bernardo, by Graciliano Ramos. Therefore, this essay centers itself in the analysis of a fragment: the $19^{\text {th }}$ chapter. As a nucleus of the tensions that characterize the novel, this excerpt holds in its form the dramatic movement between matter and subject by a distorted perspective. In its progression, the chapter apprehends the synthesis of the entire plot in three casts: a perplexity in the enunciation of experiences; a shuffle of time in the states of delirium; an inescapable return to the dark present.
PALAVRAS-CHAVE:

Graciliano Ramos;

São Bernardo;

Carpeaux

Realismo deformador;

Derrelição.

\section{KEYWORDS}

Graciliano Ramos;

São Bernardo;

Carpeaux;

Deforming realism;

Dereliction. 
E depois das memórias vem o tempo trazer novo sortimento de memórias, até que, fatigado, te recuses e não saibas se a vida é ou foi.

Que confusão de coisas ao crepúsculo! Que riqueza! sem préstimo, é verdade.

Bom seria captá-las e compô-las num todo sábio, posto que sensível:

(Drummond)

"As cordiais relações com dementes agora me pareciam significativas: era possivel que houvesse entre nós alguma semelhança. Um doido lúcido."

(Graciliano Ramos)

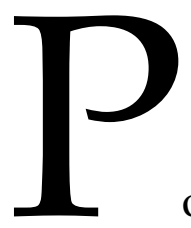

osto no exato meio de São Bernardo, como uma fenda aberta entre os movimentos díspares que forjam o romance, o capítulo 19 condensa passado e presente, melancolia e remorso, num emaranhado, e com isso atira o narrador às zonas do delírio. Suspende-se a linha reta dos fatos e emerge outra vez o sujeito da escrita, deslizando assim o discurso na curva das memórias. Se o desconcerto das páginas iniciais se prende à impossível alienação da voz narrativa e logo reflui durante a primeira parte do relato, ora a crise se instala em grau de maior intensidade, à medida que se fundem os fios de sua desdita. Sem atingir no presente o cerne do trágico - motivo tanto do drama como do livro -, Paulo Honório já não é capaz de discernir as esferas do tempo, enfim transfundidas, e resvala num turvamento fantástico: deformam-se, e não se apagam, as imagens da atualidade e do pretérito, mergulhado o espírito na confusão entre os dois.

Esse fragmento notável se articula, na trama da escrita, com as margens do romance, o princípio e o fim, momentos em que o narrador encara os problemas da expressão, aqui tão necessária quanto insuficiente. Os capítulos 1 e 2 refletem, com sinais invertidos, os planos da tensão 
entre o pragmático e o intuitivo: recompor a própria vida pela divisão do trabalho é empresa inconseqüente, porque há uma demanda interior que o estilo alheio não pode capturar; tampouco cabe esquecer a demanda, e ao sujeito resta perseguir solitário o sentido do que viveu. Quando afasta as letras sob encomenda, Paulo Honório acusa a falta da pessoa no discurso e termina envolto por sons e visões pungentes, sobretudo o pio da coruja; em seguida, o eco desse pio arranca a narração, mas esta não ganha fluidez ("Continuemos. Tenciono contar a minha história. Difícil."), antes insinua o avesso das coisas num paradoxo: "digo a mim mesmo que esta pena é um objeto pesado" - a frase constitui, aliás, o índice de ambigüidade que pouco a pouco vai crescendo no passo do livro. O último capítulo retorna ao presente e modula um balanço arrasador do roteiro revisto nas memórias, cuja matéria nem o tempo nem a escrita chega a penetrar. Distante dois anos do evento trágico, a morte de Madalena, o narrador há quatro meses procura descascar fatos, entregue à intimidade, porém o esforço não o conduz ao núcleo de seu drama, apenas o paralisa na fronteira do patético, esse intervalo de agonia e vazio que se rasga entre a ação e a consciência: "Tentei debalde canalizar para termo razoável esta prosa que se derrama como a chuva da serra, e o que me apareceu foi um grande desgosto. Desgosto e a vaga compreensão de muitas coisas que sinto." E ainda no fim estão em choque insolúvel as duas faces de seu caráter: tenta dominar rígido o rumo das palavras ("canalizar para termo razoável"), mas a prosa cumpre o regime de uma natureza infensa à objetividade, segundo o belo símile das águas que escorrem na serra. O resultado, embora escasso, indica os efeitos da expressão, pois o falso orgulho já se muda em desgosto e uma intuição vaga rompe o abafamento, nos limites do indivíduo. O resto é silêncio.

Não passou despercebido o alto relevo do trecho. Lúcia Miguel Pereira, ao resenhar São Bernardo em 1934, admira no texto a "estranha beleza, revelando no autor uma grande maestria e um raro poder de sugestão", graças à atmosfera de crepúsculo na qual soa "uma nota de ternura". ${ }^{1}$ Antonio Candido observa, no arranjo do estilo, o trânsito "da vontade de construir à vontade de analisar", que se adensa e obtém coesão com o monólogo interior, raiz dos sentimentos e da rememoração, cujo signo mais elevado se encontra no capítulo 19, "mistura de realidade presente e representação evocativa" . ${ }^{2}$ João Luiz Lafetá salienta a presença avassaladora da subjetividade justo nos instantes em que a escrita adquire realce, e distingue o teor dúbio do trecho. ${ }^{3}$

\footnotetext{
${ }^{1}$ Pereira, Lúcia Miguel. "São Bernardo e o mundo seco de Graciliano Ramos”. In: A Leitora e seus Personagens. Rio de Janeiro: Graphia, 1992.

${ }^{2}$ Candido, Antonio. Ficção e Confissão. São Paulo: Editora 34, 1999.

${ }^{3}$ Lafetá, João Luiz. “O mundo à revelia”. IN: A Dimensão da Noite. São Paulo: Editora 34, 2004.
} 
Além de firmar um vértice no centro do romance, o capítulo 19 grava um ponto de inflexão no ritmo da história, conforme faz guinar o compasso das lembranças da ventura (ascensão econômica) para o infortúnio (revés afetivo). A segunda parte do enredo, rente à figura de Madalena, se afina pelo diapasão instável da memória que novamente turva o olhar. Em seu desenho, o capítulo apreende uma síntese formal de toda a narrativa com três passagens: perplexidade na enunciação das vivências; embaralhamento dos tempos em estado de delírio; volta sem escape ao escuro presente.

Em simetria com o começo do romance, os parágrafos iniciais apresentam a tensão nascida de perfis incompatíveis, primeiro a professora e o coronel, e depois o coronel e o seu reverso sensível:

Conheci que Madalena era boa em demasia, mas não conheci tudo de uma vez. Ela se revelou pouco a pouco, e nunca se revelou inteiramente. A culpa foi minha, ou antes a culpa foi desta vida agreste, que me deu uma alma agreste.

E, falando assim, compreendo que perco o tempo. Com efeito, se me escapa o retrato moral de minha mulher, para que serve esta narrativa? Para nada, mas sou forçado a escrever. ${ }^{4}$

Aos olhos do proprietário, a bondade da mulher é excessiva, amplamente contrária a seu feitio prático e ambicioso, porém o contrário reponta agora menos simples. Descobrir que Madalena é boníssima não basta para lhe definir o caráter, e assim a complexidade do outro lança em dúvida a própria imagem. Há um senso perplexo a tornear a dicção do narrador; cada palavra traz em si uma nuança, uma suspeita do relativo que a ideia deve frisar. De frase a frase, o mesmo termo surge sob o matiz oposto: conheci, não conheci; se revelou, nunca se revelou; a culpa, ou antes a culpa; vida agreste, alma agreste. Os períodos se encadeiam em quatro pares que denotam bem as ondas de um desconcerto, pois a voz já não se ancora na certeza e portanto precisa modalizar os vocábulos, partidos em dobras. À medida que lhe fogem os objetos do passado, a narração emperra, e Paulo Honório tenta ainda abarcá-los num vaivém pendular, mas isso o leva a intuir os traços da ambigüidade. Na concentração dessas linhas, remira as peças de sua história e não as concatena, ou melhor, as peças provocam nele uma nova mirada. Madalena se impõe como enigma e, morta, lhe comunica uma inquietude à feição de fantasma que a um só tempo embaraça e estende a perspectiva; o estranhamento diante do outro suscita a dúvida a respeito de si mesmo, o que faz remorder a culpa, mas também reconhecer-se alvo de um dolo. O arco da infelicidade se fecha por todos os lados - o gesto áspero destrói tudo em redor, e não

4 Ramos, Graciliano. S. Bernardo. Rio de Janeiro: José Olympio, 1953. 
sendo nada senão ilusão de potência, se mostra antes corruptor de quem o move. Acima da alma agreste, está a vida agreste, e abaixo desta os muitos infelizes, ora carrascos ora vítimas.

Sobrevém então a fala indecisa que outra vez cava uma fresta no presente, cortando o fio do enredo. A consciência só parece avançar quando há um declínio da razão: "compreendo que perco o tempo". Sublinhe-se a diferença entre as noções de perder o tempo e perder tempo - esta se liga ao esperdício de energia, enquanto aquela submerge o juízo no cronos psicológico. Com isso, aflora à visão o verdadeiro desígnio das palavras ("o retrato moral de minha mulher"), dramaticamente escapável, o qual se cruza com o anterior ("contar a minha vida") para desorientar as ideias ou sugerir distinto oriente, perdido de saída. Inútil a pergunta por finalidades; a resposta é nula e plena. Colidem aí o ângulo sóbrio ("Para nada") e o ângulo desmedido ("mas sou forçado a escrever"), de maneira que expansão e limite crispam o ânimo e ditam o andamento do texto: "Às vezes as ideias não vêm, ou vêm muito numerosas - e a folha permanece meio escrita, como estava na véspera." A impressão da página pela metade espelha na grafia um tumulto interno, "emoções indefiníveis", duelo de forças que aperta os nós do conflito e faz tresandar a inteligência; o desejo de volta às cenas do pretérito, a fim de corrigir os erros e ajustar as falas com a mulher, como se pudesse restabelecer o diálogo suspenso, se traduz novamente em quebra de perspectiva. "Saudade? Não, não é isto: é desespero, raiva, um peso enorme no coração." - nenhum tempo lhe oferece repouso, nostalgia e fúria se cancelam, e juntas viram angústia.

Sabemos o que vai no coração de Paulo Honório, um peso enorme. E nas rodas de seu monólogo, a atitude lírica se ensombra nos interditos da memória: "Procuro recordar o que dizíamos. Impossível. As minhas palavras eram apenas palavras, reprodução imperfeita de fatos exteriores, e as dela tinham alguma coisa que não consigo exprimir." Procuro recordar - não consigo exprimir. Se de um lado se empenha em recordar (repor no coração) as conversas com Madalena para talvez decifrá-las, de outro resiste o alcance falho das palavras, que não se aliviam do peso. Entre as duas pontas, salta a desarmonia evidente no campo da linguagem, direta ou alusiva; reconhece agora ter sempre pronunciado um reflexo de exterioridades e se aflige ao buscar alguma coisa oculta nas entrelinhas. O que antes obstava a concórdia no diálogo se projeta na fala do narrador. Tentando esfumaçar o mundo concreto, apagava as luzes a ver se sentia por dentro as palavras da mulher na noite, espaço simbólico do inconsciente. Os sons naturais avultavam no clima difuso (a arenga dos sapos, o gemido do vento, o canto dos grilos), mas os sentidos não esmoreciam de todo e o coronel ainda chamava o capanga alerta: “- Casimiro!". Nessa hora, enquanto escreve, repara o cair da noite e os sinais da natureza, afundan- 
do na treva dissolvente, no entanto também aqui há um resto de vigilância a perceber o tique-taque longínquo do relógio e a suster o ânimo na meia-luz de crepúsculo. Mesclam-se as esferas do tempo e a voz exclama rude: "- Madalena!", para logo depois sussurrar: "- Madalena...", frente à aparição comovedora: "Também já não a vejo com os olhos."

Progressivamente, o discurso se anuvia em torvelinho, embaçando espectros e coisas na penumbra, arrojando o espírito num abismo de antíteses. Delírio. Raivoso e sereno, Paulo Honório discute com a mulher e pondera a própria desrazão, atordoado por figuras que se duplicam remotas e atuais, giram os anos em espiral. De repente, risca a atmosfera um estrídulo, o pio da coruja. O pensamento quer investigar os níveis da vertigem: "Terá realmente piado a coruja? Será a mesma que piava há dois anos? Talvez seja até o mesmo pio daquele tempo." - são duas interrogações de apelo realista e ambas confluem na frase absurda, o trinado supra-acústico do mau agouro. Julga escutar o rumor antigo da casa, uma palestra de seu Ribeiro e d. Glória, em paralelo com os ruídos próximos, a empregada, o papagaio, o cachorro, os bois; trata-se de uma esquisita barafunda que engolfa a consciência no limiar da alucinação, entrança as várias dimensões do vivido e não permite fuga. $\mathrm{O}$ exaspero deriva da amálgama insólita de avessos que nele se cruzam: "Agitam-se em mim sentimentos inconciliáveis: encolerizo-me e enterneço-me; bato na mesa e tenho vontade de chorar." Imagina finalmente ter vez de persuadir Madalena a se render à paz do convívio, mas nada dissipa a incomunicabilidade e, terrível, desponta do transe o inexorável posto no futuro: "O que vai acontecer será muito diferente do que esperamos." Termina o delírio.

A pedido do amigo João Condé, Graciliano redigiu, em 1947, um testemunho sobre a preparação de São Bernardo, no qual se lê: "Até o capítulo XVIII tudo ocorreu sem transtorno. Um dia de fevereiro, ao entrar em casa, senti arrepios. À noite, com febre, fiz o capítulo XIX, uma confusão que mais tarde, quando me restabeleci, conservei." Apesar de parecer improvável que o autor haja escrito sob tal estado, a nota serve para advertir uma séria inflexão de ritmo no capítulo 19, em que o narrador, este sim, declina febril. O delírio, ao invés de ferir o realismo do romance, serve como solução formal ao apanhar o protagonista nos rodeios torturados de seu drama, à medida que extravasa as bordas da memória e atravessa a subjetividade. Resulta daí o problema, na intersecção da cegueira que o raso da lucidez causaria com o entorpecimento que viria da loucura - o delírio, assim, deforma o realismo estrito para melhor invadir a realidade.

Graciliano comenta ainda, no testemunho, a sua internação após a febre: "A doença prendeu-me à cama três ou quatro meses. Viagem a Maceió, exames, diagnósticos equívocos, junta médica, entrada no hospital, operação, quarenta e tantos dias com um tubo de borracha a atravessarme a barriga, delírios úteis na fabricação de um romance e de alguns con- 
tos, convalescença morosa." 5 Com efeito, a experiência pessoal de desatino, quando da enfermidade, lhe empresta um meio de sondar na técnica literária, baralhando a psique, os pontos de tensão entre sujeito e objeto, tempo e espaço, engenhosamente intricados graças à dialética de sua arte realista. $\mathrm{O}$ autor refere a utilidade que extraiu do fenômeno para conceber o pesadelo em Angústia e alguns contos, como por exemplo "O relógio do hospital" e "Paulo", do volume Insônia. No tocante a esses dois textos, feitos na prisão, explica nas Memórias do Cárcere o contorno das obsessões: "as pancadas do relógio tomavam forma, ganhavam nitidez e mudavamse em bichos; supunha-me dois, um são e outro doente, e desejava que o cirurgião me dividisse, aproveitasse o lado esquerdo, bom, e enviasse o direito, corrompido, para o necrotério. Essa parte direita, infeccionada, era um hóspede sem-vergonha e chamava-se Paulo." 6

Não seria demais supor então, segundo as circunstâncias descritas ("Paulo" calca-se em sensação íntima, experienciada aliás durante o arranjo de São Bernardo), que o desdobramento diz respeito à intrusão da personagem na mente do criador. No conto, o enfermo se agasta sedado nas nuvens do delírio, navega num todo confuso, mistura de frações presentes e passadas com o horror de carregar em si um duplo cruel; anseia que o seccionem e lhe extirpem o lado direito, podre. Paulo é um ente ameaçador e silencioso, espreita-o há dois meses e sorri amarelo esparramando-se no quarto. Porém, ao final, cessa o sonho de purificar-se inteiramente esquerdo e bom, e o doente reconhece a familiaridade estranha: "O que estou dizendo, a gemer, a espojar-me, é falsidade. Paulo compreende-me. Curva-se, olha-me sem olhos, espalha em roda um sorriso repugnante e viscoso que treme no ar."7 Do mesmo modo que o fazendeiro persiste em alijar da alma as fraquezas, tornadas forças para vencer o mundo, o autor reversamente espera despejar de si a face malévola ${ }^{8}$; ambos fracassam, porque têm de deparar com a ambigüidade que os sustenta. "Paulo compreende-me": o verbo compreender significa, no contexto, tanto o entendimento entre os dois quanto a impregnação recíproca do criador em Paulo. Com isso, percebe-se que a honestidade do

\footnotetext{
5 Ramos, Graciliano. "Paulo Honório". IN: 10 Romancistas Falam de seus Personagens. Rio de Janeiro: Edições Condé, 1947.

${ }^{6}$ Ramos, Graciliano. Memórias do Cárcere. Rio de Janeiro: José Olympio, 1953.

${ }^{7}$ Ramos, Graciliano. “Paulo". In: Insônia. Rio de Janeiro: José Olympio, 1955.

${ }^{8}$ Em outro testemunho acerca de suas invenções, Graciliano se refere a Paulo Honório: “É possível que esse sujeito reflita alguma tendência que no autor existisse para matar alguém, ato que na realidade não poderia praticar um cidadão criado na ordem, acostumado a ver o pai, homem sisudo e meio termo, pagar o imposto regularmente." E considera, no fim, o reflexo oblíquo do seu caráter sobre as personagens: "Todos os meus tipos foram constituídos por observações apanhadas aqui e ali, durante muitos anos. É o que penso, mas talvez me engane. É possível que eles não sejam senão pedaços de mim mesmo e que o vagabundo, o coronel assassino, o funcionário e a cadela não existam." ("Alguns tipos sem importância". IN: Linhas Tortas. São Paulo: Martins, 1970.)
} 
artista, ao estudar os caracteres, exige avaliar no outro o que lhe é particular e crítico, sob o viés da angústia que distorce e ilumina os planos da realidade.

Num episódio do cárcere, quando não pode divisar em seus recessos o que o move a esta ou àquela reação, Graciliano gradua a pesquisa da própria inconstância ao raio da pluralidade:

Sei lá o que se passava no meu interior? Difícil sermos imparciais em casos desse gênero; naturalmente propendemos a justificar-nos, e é o exame do procedimento alheio que às vezes revela as nossas misérias íntimas, nos faz querer afastar-nos de nós mesmos, desgostosos, nos incita a correção aparente. Na verdade, vigiando-me sem cessar, livrava-me de exibir sentimentos indignos. Afirmaria, porém, que eles não existiam? Tudo lá dentro é confuso, ambíguo, contraditório, só os atos nos evidenciam, e surpreendemo-nos, quando menos esperamos, fazendo coisas e dizendo palavras que nos horrorizam. ${ }^{9}$

Otto Maria Carpeaux, a fim de examinar certa tendência estilística dos anos 30, recupera o conceito de "realismo mágico", antes apontado por teóricos europeus. Trata-se de um modo de representar os problemas para além do registro objetivo da superfície, descendo às funduras por meio de uma técnica deformadora: "Essa deformação intencional pode ser seletiva, como no realismo tradicional, ou ideológica, como no realismo socialista. Também poderia ser fantástica ou, como por volta de 1930 se dizia, "mágica'". E dentre os exemplos que observa nessa terceira via, colhidos nas várias tradições literárias, menciona o brasileiro Graciliano Ramos com Angústia: “o véu daquela realidade levantou-se e o fundo dela ficou magicamente iluminado por uma técnica novelística que emprega recursos da psicologia do sonho." 10 O primeiro experimento de realismo deformador (ou mágico) na obra se encontra, a meu ver, no capítulo 19 de São Bernardo. Efetivamente, Carpeaux estende a impressão, em ensaio célebre, aos diversos títulos como estilo do autor: "É assim com todos nós outros, quando entramos no mundo empastado e nevoento, noturno, onde os romances de Graciliano Ramos se passam: no sonho. Os hiatos nas recordações, a carga de acontecimentos insignificantes com fortes afetos inexplicáveis, eis a própria 'técnica do sonho', no dizer de Freud." A força diluidora da representação aboliria, assim, os limites de prisma, enervando o tecido ficcional, para atingir o pathos de uma negatividade: "Os romances de Graciliano Ramos são experimentos para acabar com o sonho de angústia que é esta vida."11 $\mathrm{O}$ estilo descarnado, rigorosamente essen-

\footnotetext{
${ }^{9}$ Ramos, Graciliano. Memórias do Cárcere. Rio de Janeiro: José Olympio, 1953.

${ }^{10}$ Carpeaux, Otto Maria. Tendências Contemporâneas da Literatura. Rio de Janeiro: Tecnoprint, [s.d.].

${ }^{11}$ Carpeaux, Otto Maria. "Visão de Graciliano Ramos". IN: Ensaios Reunidos. Rio de Janeiro: Topbooks, 1999.
} 
cial, trai o desejo de eliminar a História na dissolvência do indivíduo ${ }^{12}$ “Não é bom vir o diabo e levar tudo?", pergunta Paulo Honório, trágico.

Atento à matriz negativa da expressão, Alfredo Bosi considera, em diferentes momentos, o travo doloroso que da persona do escritor se transfere às suas criaturas. Como Carpeaux, Bosi realça o problemático a instruir a visão e o estilo. Os enredos e tipos perfazem o signo da fratura, que é social e moral, e moldados pelo pincel da singularidade guardam em comum "o dissídio entre a consciência do homem e o labirinto de coisas e fatos em que se perdeu." $13 \mathrm{O}$ insulamento grave do autor, refratário às propostas de seu tempo, se tinge de radicalidade e gera a escuridão. ${ }^{14}$ Com efeito, analisando os livros de corte biográfico, o crítico esmiúça o senso de vigília que incide sobre as imagens e os seres, reparte-os em dúvida. Nas memórias da cadeia, o empenho compreensivo se recobre de opacidade, truncado a todo instante, porque o olhar que sonda a si mesmo e ao outro não ignora os contrastes, e o mundo se ofusca num borrão: "A perspectiva dominante é a que vai da interrogação à estranheza e, nos casos extremos, fecha-se em recusa. Não é um realismo solar, é um realismo plúmbeo." O chumbo - em suas acepções de cor, peso e ânimo baliza a tonalidade do testemunho. $\mathrm{O}$ cinzento também se dissemina, neblinoso, nas páginas da ficção, lacerante nas vozes de narradores cujas letras não bastam para expurgar o passado ou comunicá-lo ao próximo: “Um sentimento turvo que nada parece apaziguar, pois não é nem a contrição do arrependido, nem o mergulho nas águas tépidas da autocomiseração." 15 Em sua leitura de Infância, Bosi medita nas inflexões do autor ao descrever a paisagem, ora firme no claro do realismo solar, ora inseguro nas nuvens do realismo vigilante; e ao descrever os entes da família, cerceado pela educação bárbara, erra no labirinto do realismo febril: "A condição de impotência em face do outro beira o absurdo e estará na raiz da

\footnotetext{
12 Em ensaio posterior, Carpeaux deduz o sentido ideológico radicado na expressão do "lírico estranho": "É esse poder de estilização literária que se encontra com a vontade política de 'estilizar a sociedade', eliminando dela as contradições intrínsecas. Desse modo, o 'libelo contra a humanidade' transforma-se em seqüência de acordes, cujo último é o mais intenso dos acordes musicais, o silêncio." ("Graciliano e seu intérprete". IN: Teresa - revista de literatura brasileira, n. 2. São Paulo: USP/Editora 34, 2002. Texto originalmente publicado em O Jornal, Rio de Janeiro, em 23 de fevereiro de 1947.)

${ }^{13}$ Bosi, Alfredo. História Concisa da Literatura Brasileira. São Paulo: Cultrix, 1994.

${ }^{14}$ Em debate sobre a posição de Graciliano no quadro da cultura nacional, Bosi opina: "Agora, essa visão, tão crítica, não é nem dos modernistas, nem dos regionalistas. Então, eu acho que fica na nossa cabeça o problema: como se formou? Talvez ainda tenhamos, um dia, de fazer a biografia espiritual de Graciliano. Como se formou nele uma crítica tão radical, tanto ao projeto burguês, como ao que nós chamaríamos hoje de populismo, folclorismo, assim por diante... A rejeição dele é total. Talvez essa escuridão da obra dele venha de que realmente os projetos em curso não o atraíam." ("Mesa-redonda" In: Bosi, Alfredo et alii. Graciliano Ramos - Coleção Escritores Brasileiros. São Paulo: Ática, 1987.)

${ }^{15}$ Bosi, Alfredo. "A escrita do testemunho em Memórias do Cárcere". In: Literatura e Resistência. São Paulo: Cia. das Letras, 2008.
} 
reiterada expressão de perplexidade do narrador que se diz incapaz de encontrar sentido nas ações alheias e, às vezes, nas próprias." 16 Essas categorias, e o movimento que as enfeixa no corpo de cada obra, valem para pensar a prosa inteira de Graciliano Ramos.

Tal alcance de arte literária apenas se consuma em virtude de um tratamento deformador da realidade, esgarçando o perímetro do realismo obtuso sem deixar de ser autenticamente realista. Dostoievski, no conto "Krotkaïa", inserido no Diário de um Escritor, adverte os leitores com respeito à sua ideia de relato fantástico: "Classifiquei este conto como fantástico, embora o considere real, no mais alto grau. Mas tem certo aspecto fantástico, principalmente quanto à forma"; o entrecho do conto, que aliás em parte semelha o de São Bernardo (trata-se da fala contínua de um prestamista alucinado ante o cadáver da mulher suicida, com quem jamais se conciliou), não rompe os contornos reais, a forma, esta sim, é insólita, e o criador russo explica: "Procurei seguir o que me pareceu a ordem psicológica. Essa suposição de um taquígrafo anotando todas as palavras do desgraçado é que se me afigura o elemento fantástico do conto. A arte não repele este gênero de procedimento." 17 Entende-se, logo, por que Dostoievski se definiu, no Diário, como um "realista da alma humana". Formalmente, o capítulo 19, e mesmo todo o romance, é fantástico, ou mágico, dada a verossimilhança do ponto de vista, afinal quem pode narrar o próprio delírio enquanto o vivencia? Ou ainda, seria crível um homem rude compor livro tão complexo? Entretanto, é esse expediente que permite ao autor captar a real "ordem psicológica" da personagem, desvelando o mundo à sua volta: a tragédia de Paulo Honório, repisada nos círculos da memória, faz ecoar o nosso fracasso. Em termos poéticos, a lição vem de Aristóteles: "Do ângulo da poesia, um impossível convincente é preferível a um possível que não convença." 18

A última passagem do fragmento assinala o remate do desvario. Finda-se a atmosfera de crepúsculo; porém não ascende o tino à claridade, inunda-se em treva espessa.

Há um grande silêncio. Estamos em Julho. O nordeste não sopra e os sapos dormem. Quanto às corujas, Marciano subiu ao forro da igreja e acabou com elas a pau. E foram tapados os buracos de grilos.

Repito que tudo isso continua a azucrinar-me.

O que não percebo é o tique-taque do relógio. Que horas são? Não posso ver o mostrador assim às escuras. Quando me sentei aqui, ouviam-se as

\footnotetext{
${ }^{16}$ Bosi, Alfredo. "Passagens de Infância de Graciliano Ramos". In: Entre a Literatura e a História. São Paulo: Editora 34, 2013.

${ }^{17}$ Dostoievski. Diário de um Escritor. Rio de Janeiro: Tecnoprint, [s.d.].

18 Aristóteles. "Arte poética". IN: Aristóteles, Horácio, Longino. A Poética Clássica. São Paulo: Cultrix, 1981.
} 
pancadas do pêndulo, ouviam-se muito bem. Seria conveniente dar corda ao relógio, mas não consigo mexer-me. ${ }^{19}$

A sinfonia caótica que o envolvia - vento, sapos, corujas e grilos apaga-se, em verdade não existiu. Existe, agudo, o silêncio de uma noite de inverno. Agora o juízo reconhece as sombras que se infiltraram no presente para embaciá-lo, mas nem por isso se descarrega dos tormentos. $\mathrm{O}$ que já não se manifesta no concreto ressoa dramático na consciência, salta no tempo e atazana perpétuo. Em derrelição, o narrador sente esfumarem-se as antíteses e desliza no vazio irremediável: a natureza e a máquina emudecem, nada sustenta a alma. Paralítico, Paulo Honório não pode dar corda ao relógio (metaforicamente recobrar a cronologia produtiva), e tampouco se pode acolher no fluxo espontâneo (deste há tão-só resíduos). Encarna, no fim, uma tragédia sem catarse. Ao herói, não socorre a morte ou a remissão; ao leitor, restam as perguntas sem resposta. Tragédia moderna, o romance encena peripécias equívocas, deforma a vida em delírio - a angústia continua.

Erwin Torralbo Gimenez é professor de Literatura Brasileira na Universidade de São Paulo. Graduado e Doutor em Letras também pela USP, é autor de artigos acadêmicos, como "Graciliano Ramos, uma poética da insignificância" (Revista do Instituto de Estudos Avançados), e organizou, com Beth Ramos, a edição comemorativa dos 80 anos do romance Caetés.

${ }_{19}$ Ramos, Graciliano. S. Bernardo. Rio de Janeiro: José Olympio, 1953. 